\title{
STRUCTURAL AND THERMAL PROPERTIES OF NANOCOMPOSITES BASED ON POLYOLEFINS AND MONTMORILLONITE MODIFIED WITH ETHYL 2-AMINOBENZOATE
}

\author{
Ewa Olewnik-Kruszkowska' ${ }^{1}$, Ewelina Chrzanowska ${ }^{1}$
}

Nicolaus Copernicus University in Toruń, Faculty of Chemistry, Chair of Physical Chemistry and Physicochemistry of Polymers, Gagarin 7 Str., 87-100 Torun, Poland, e-mail: olewnik@umk.pl, ewelinachrzanowska@gmail.com

Received: 2017.05 .15 Accepted: 2017.08.01 Published: 2017.09.03

\begin{abstract}
Our efforts were focused on improving thermal stability of polyethylene (PE) and polypropylene (PP) through incorporation of new organically modified montmorillonite. The reactive organofilic montmorillonite (MMT-EA) was prepared by exchanging the interlayer inorganic cations in montmorillonite by a large excess of ethyl 2-aminobenzoate (EA). Organic modification can affect not only microstructures, but also the properties of the polymer - montmorillonite nanocomposites. In the next step, novel polyolefins/ organoclay nanocomposites were prepared by melt intercalation process. In order to obtain this new family of materials and enhance their properties very low filler level, from 1.5 to $5 \mathrm{wt}$.\% was used.The dispersion of the montmorillonite layers in the polymers was characterized by using X-ray diffraction (XRD). The thermal properties and structure changes were studied by different scanning calorimetry (DSC) and thermogravimetric analysis (TGA). Further studies indicated that the exfoliated clay modified with EA improved thermal stability of the PE and PP/ MMT-EA nanocomposites.
\end{abstract}

Keywords: nanocomposites, thermal properties, polyolefins, TGA, XRD.

\section{INTRODUCTION}

In recent years polymer/clay nanocomposites have stimulated the revival of great interest in these materials: both in industry and in academia, because they often exhibit remarkable improvement of thermal stability and fire resistance in comparison with virgin polymers.

Nanocomposites are the materials commonly based on polymer matrices reinforced by nanofillers [4]. The most popular nanofillers are silica-titania oxides, precipitated silica, cellulosed whiskers, zeolites and many others [7, 6, 10]. Polymer/clay nanocomposites consist of filler in polymerized medium [9]. The preparation of nanocomposites requires extensive delamination of the layered clay structure and complete dispersion throughout the polymer matrix. Materials such as polyethylene and polypropylene with low surface energy only weakly interact with mineral surfaces, making the obtaining of polyolefin nanocomposites by melt compounding considerably more difficult [5]. Dispersing hydrophilic nanofillers in hydrophobic polymer is not easy. For this reason, it is necessary to use compatibilizing agents, which allow to disperse clay in polymer. The most popular are alkyloammonium ions because they can be exchanged easily with ions situated between the layers. The other ones are amino acids and silanes.

The most recent method used to prepare polymer-clay nanocomposites is melt intercalation of polymer into a few percent of organoclay. Two types of structures are the most popular, namely intercalated nanocomposites where the polymer chains are sandwiched in between layers of organoclay and exfoliated nanocomposites where the separated, individual layers are 
more or less uniformly dispersed in the polymer matrix. This new family of materials exhibits enhanced properties at very low filler level, usually less than $5 \mathrm{wt} . \%$ [1].

Nanocomposites are notable for their improved thermal stability and flame retardation. The successful development of nylon 6/nanoclay composites and their use in demanding applications has stimulated many research groups who have attempted to produce analogous materials [2].

The objective of this work was to characterize the influence of new modified montmorillonite on thermal stability of polyethylene and polypropylene. The extent of this influence was determined by comparison of nanocomposites to virgin polyolefins.

\section{EXPERIMENTS}

\section{Materials}

The ethyl 2-aminobenzoate (bp $268^{\circ} \mathrm{C}$ ) used as compatibilizing agent was purchased from Sigma-Aldrich. Hydrochloric acid and ethanol used in modification process were supplied by $\mathrm{POCH}$ (Poland). The montmorillonite used in this study as a nanofiller was provided by the Riedel-de Haen. Polyolefins (PE and PP) were delivered by BASELL -ORLEN POLYOLEFINS (Plock, Poland).

\section{Preparation of montmorillonite modified with ethyl 2-aminobenzoate}

The reactive organofilic montmorillonite was prepared by exchanging the interlayer inorganic cations of natural montmorillonite by a large excess of ethyl 2-aminobenzoate. In aim to obtain cations surfactant was dissolved in water and protonated with $\mathrm{HCl}$ at $80^{\circ} \mathrm{C}$. Then montmorillonite powder dispersed in a mixture of water/ethanol was slowly added into a solution of pre-dissolved stoichiometric amount of surfactant. The reaction was conducted for about $3 \mathrm{~h}$. Modified MMT was filtered and washed with water in order to remove residue of amine until no chloride ions were detected by $\mathrm{AgNO}_{3}$ solution. The initial ratio amine/clay and $\mathrm{HCl} /$ ethyl 2 -aminobenzoate were $2 \mathrm{mmol} / \mathrm{g}$ and 2 molar ratio respectively. Modified MMT has changed the color from fair ecru to intensive pink.

\section{Preparation of the nanocomposites}

The nanocomposites were prepared by melt intercalation process, in which polymer incorpo- rates itself into the interlayer space of organoclay $(1.5,3$ and $5 \% w t)$. Polymer- and organic-treated layered montmorillonite were charged into a mini- extruder.

\section{Material characterization}

Elementary analysis of the modified montmorillonite for the determination of $\mathrm{C}$ and $\mathrm{N}$ were carried out with Vario MACRO CHN Elementary Analyzer (Analysensysteme, Germany).

XRD method was used to identify intercalated structures. The angle X-ray diffraction (XRD) patterns were recorded on a X'Pert Philips diffractometer using $\mathrm{CuK}_{\text {alfa }}$ radiation. The experiments were performed in a range of $2 \theta=1-11^{\circ}$ where divergence slit size was $0.125^{\circ}$ and scan step time $25 \mathrm{~s}$. The basal spacing of the montmorillonite layer, $\mathrm{d}$, was calculated using the Bragg's equation, $\lambda=2 \mathrm{~d} \sin \theta$.

The DSC analyses were conducted on a Polymer Laboratories, Epson, GB differential scanning calorimeter under the protection of $\mathrm{N}_{2}$ with a flow rate about $15 \mathrm{ml} / \mathrm{min}$. All runs were carried out with a sample consisting of approximately 4-10 mg of nanocomposites. They were carefully put into the aluminium pan, empty aluminium pan was used as reference. The heating and cooling rate was $10^{\circ} \mathrm{C} / \mathrm{min}$.

Thermogravimetric analysis (TGA) was used for investigating physical changes in nanocomposites. TA Instruments, SPT $2960 \mathrm{Si}-$ multaneous DSC-TGA was used for studying thermal behaviors of the obtained nanocomposites. TGA traces were monitored from room temperature to $600^{\circ} \mathrm{C}$ with a $10^{\circ} \mathrm{C} / \mathrm{min}$ under air and nitrogen flow.

\section{RESULTS AND DISCUSSION}

\section{Elementary analysis}

The actual content of organic salt incorporated into the clay during modification process was determined based on the elementary analysis. In order to determine this the quantity of $\mathrm{C}$ and $\mathrm{N}$ was checked in a few treated clay and neat MMT. The quantity of the absorbed compatiblizer by $1 \mathrm{~g}$ of montmorillonite and percentage consumption of EA were determined. The results of this analysis and calculation are presented in Table 1. It can be deduced that the consumption of salt was about $37 \%$ which indicates that EA penetrates interlayer space of a nanofiller. 
Table 1. Results of elementary analysis of MMT and MMT modified with ethyl 2-aminobenzoate (MMT-EA)

\begin{tabular}{|c|c|c|}
\hline \multirow{2}{*}{ Parameter } & \multicolumn{2}{|c|}{ Sample } \\
\cline { 2 - 3 } & MMT & MMT-EA \\
\hline Weight of sample [mg] & 13.211 & 10.905 \\
\hline$\%$ C in sample [\%] & 0.822 & 16.600 \\
\hline Weight C in sample [mg] & 0.109 & 1.720 \\
\hline$\%$ N in sample [\%] & 0.062 & 2.183 \\
\hline Weight N in sample [mg] & 0.008 & 0.238 \\
\hline Weight of EA in sample [mg] & - & 2.626 \\
\hline $\begin{array}{c}\text { Weight EA per 1g MMT } \\
\text { [mg/g] }\end{array}$ & - & 317.232 \\
\hline $\begin{array}{c}\text { Quality of EA per 1g MMT } \\
\text { [mmol/g] }\end{array}$ & - & 1.923 \\
\hline$\%$ consumption EA [\%] & - & 36.255 \\
\hline
\end{tabular}

\section{XRD analysis}

$\mathrm{X}-\mathrm{RD}$ was used to observe the changes in the interlayer distances of the pristine clay and MMTEA. Figure 1 depicts the small angle X-ray diffraction patterns of both modified (MMT-EA) and unmodified (MMT) montmorillonite clays. The X-ray diffractogram of the modified clay revealed a shift in the position of (d 001) planes corresponding to an increase of the basal spacing of the clays by exchange of interlayer cations with EA cations. The peak value of 2 theta for MMTEA was $5.3^{\circ}$, which was smaller than that of the pristine clay $\left(6.2^{\circ}\right)$. The basal spacing on MMT moves from $1.42 \mathrm{~nm}$ to $1.66 \mathrm{~nm}$ for the modified clay and confirms the occurrence of salt molecule intercalation between montmorillonite clay layers. These clay was then used to prepare polyolefinsclay nanocomposites by melt blending.



Fig. 1. X-ray diffractograms of unmodified (MMT) and modified (MMT-EA) montmorillonite
In an attempt to evaluate whether the nanocomposite structure was formed or not, the dispersion of MMT-EA clay in the polyolefins matrix was analyzed by XRD.

The XRD patterns for the organoclays and $\mathrm{PE} /$ clay composites containing from 1.5 to $5 \mathrm{wt} \%$ of the MMT-EA are shown in Figure 2a while Figure $2 b$ provides similar information for polypropylene-based composites.

Good compatibility between the modified clay and polymer matrixes can be observed for composites containing $1.5 \mathrm{wt} \%$ of nanofiller. The characteristic peak disappeared which suggests that the exfoliated nanocomposites were formed.

As shown in Figure $2 \mathrm{a}$ and Figure 2b, the XRD patterns of the other nanocomposites reveal small broad diffraction peak between 2 theta values of $5^{\circ}$ and $7^{\circ}$ when the clay content was increased above $1.5 \mathrm{wt} \%$. Substantial reduction in the intensity of the diffraction peak derived from the interlayer spacing of the clay allows to assume that almost complete exfoliation of the MMT layers took place and nanocomposite structure was obtained. The width of the peak indicates that there may be an immiscible com-
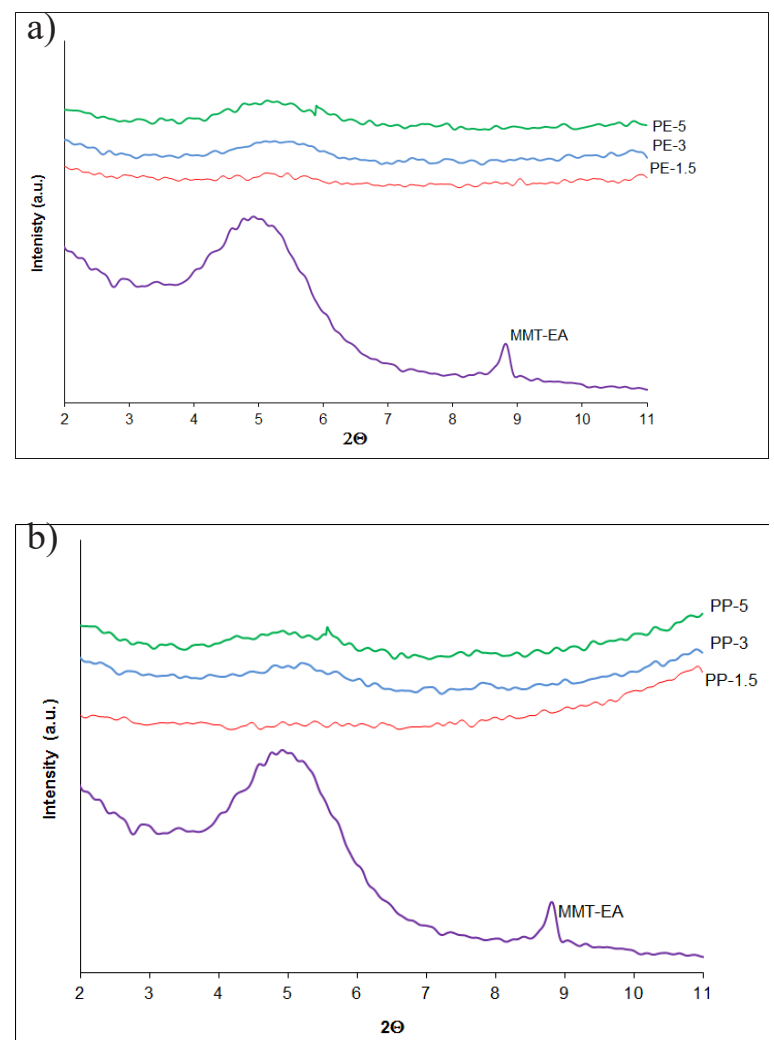

Fig. 2. XRD patterns of: (a) PE and PE/clay nanocomposites, (b) PP and PP/clay nanocomposites 
ponent as well. This implies that the nanocomposites included some stacked clays above this clay content. On this basis, we can conclude that the compound is formed by a nanocomposite together with a microcomposite.

We also note in Figure 2a that the small peak for $3 \mathrm{wt} \%$ and $5 \mathrm{wt} \%$ nanocomposites is larger in comparison with that of MMT-EA clay. For this reason it can be deduced that some organic material was extracted from the MMT-EA interlayers during melt mixing. The same phenomenon is clearly seen in Figure 2b, for PP nanocomposites.

\section{Thermal properties}

DSC analysis has been carried out to study the glass transition and melting temperature of the PE/MMT-EA and PP/MMT-EA nanocomposites. The $\mathrm{T}_{\mathrm{g}}$ of the PE/MMT-EA nanocomposites was decreased remarkable as the MMT-EA content increased (Table 2). This is clearly caused by a strong interaction between MMT-EA and PE, which limits the cooperative motions of the PE main chain segments [6]. This decrease may be attributed to higher interfacial area and adhesion between the matrix and exfoliated clay, which would act to reduce the mobility of crystallizable chain segments [5]. The DSC thermograms for pure polyethylene and its nanocomposites have shown that pure polymer exhibits an endothermic peak approximately at $112.9^{\circ} \mathrm{C}$ and glass transition temperature $\left(\mathrm{T}_{\mathrm{g}}\right)$ at $-77.5^{\circ} \mathrm{C}$. The $\mathrm{T}_{\mathrm{m}}$ of $\mathrm{PE} /$ MMT-EA nanocomposites is slightly higher than that of PE. The $\mathrm{T}_{\mathrm{m}}$ of PE with $5 \% \mathrm{wt}$ of MMTEA is $116.4^{\circ} \mathrm{C}$ This is tentatively ascribed to the confinement of the polymer chains adjacent to the montmorillonite layers that prevents the segmental motion of the polymer chains [2].

Table 2. Melting and glass temperature of nanocomposites as a function of MMT-EA content

\begin{tabular}{|c|c|c|}
\hline Sample & $\mathbf{T}_{\mathbf{g}}\left[{ }^{\circ} \mathbf{C}\right]$ & $\mathbf{T}_{\mathbf{m}}\left[{ }^{\circ} \mathbf{C}\right]$ \\
\hline PE & -77.5 & 112.9 \\
\hline PE-1.5\% & -79.1 & 116.5 \\
\hline PE-3\% & -81.9 & 118.0 \\
\hline PE-5\% & -84.5 & 116.4 \\
\hline PP & - & 172.3 \\
\hline PP-1.5\% & - & 174.3 \\
\hline PP-3\% & - & 170.3 \\
\hline PP-5\% & - & 172.4 \\
\hline
\end{tabular}

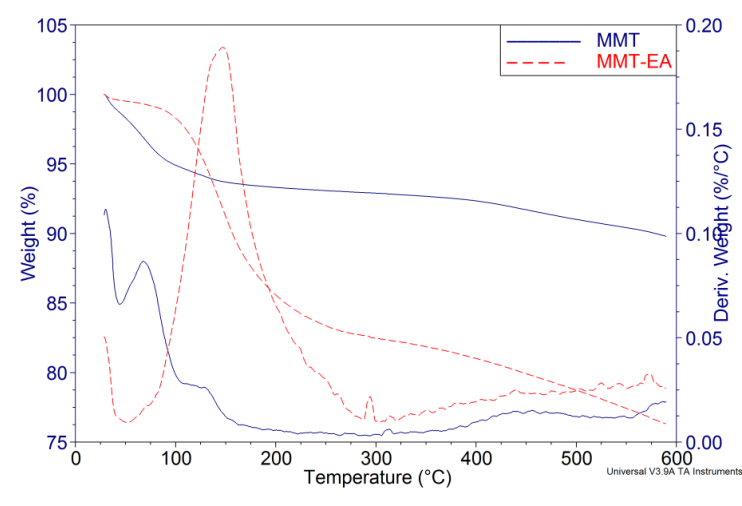

Fig. 3. TGA and DTG curves for unmodified (MMT) and modified montmorillonite (MMT-EA)

The observed decreasing of $\mathrm{T}_{\mathrm{g}}$ and increasing of $\mathrm{T}_{\mathrm{m}}$ for PE/MMT-EA nanocomposites is not observed in the case of nanocomposites based on PP and organo-modified montmorillonite. During the analysis of PP/MMT-EA nanocomposites no changes have been noted.

Figure 3 shows the TGA and DTG curves for unmodified (MMT) and modified montmorillonite (MMT-EA) which were used in this work. It is apparent from this study that there is a significant variation in the initial degradation temperatures. For the natural clay an initial weight loss between 20 and $200^{\circ} \mathrm{C}$ is observed due to residual water. There was also a decomposition between 400 and $600^{\circ} \mathrm{C}$ what can be connected with dehydroxylation of the aluminosilicate [3]. For the MMT-EA weight losses at $100-300{ }^{\circ} \mathrm{C}$ are assigned to salt decomposition. The thermo-oxidative degradation of ammonium salts proceeds by a Hofmann reaction to give a product different from the amine, or an SN2 nucleophilic substitution reaction to produce the amine [8]. Also the presence of oxygen and metallic ions in the clay mineral structure can lead to catalytic reactions for further oxidative scission of alkenes, what was studied by Xie et al [11].

The water content was also calculated and the results show that for the natural MMT content was much higher $(5.1 \mathrm{wt} \%)$ than that for the MMT-EA sample (2.0 wt $\%$ ), probably due to a reduction of a hydrophilic nature of the clay after modification.

It is well known that clay layers have good barrier action, which can improve the thermal stability of polymer/clay nanocomposites. But we have to remember that clay itself and the incorporated cations in the organoclay, due to Hofmann 

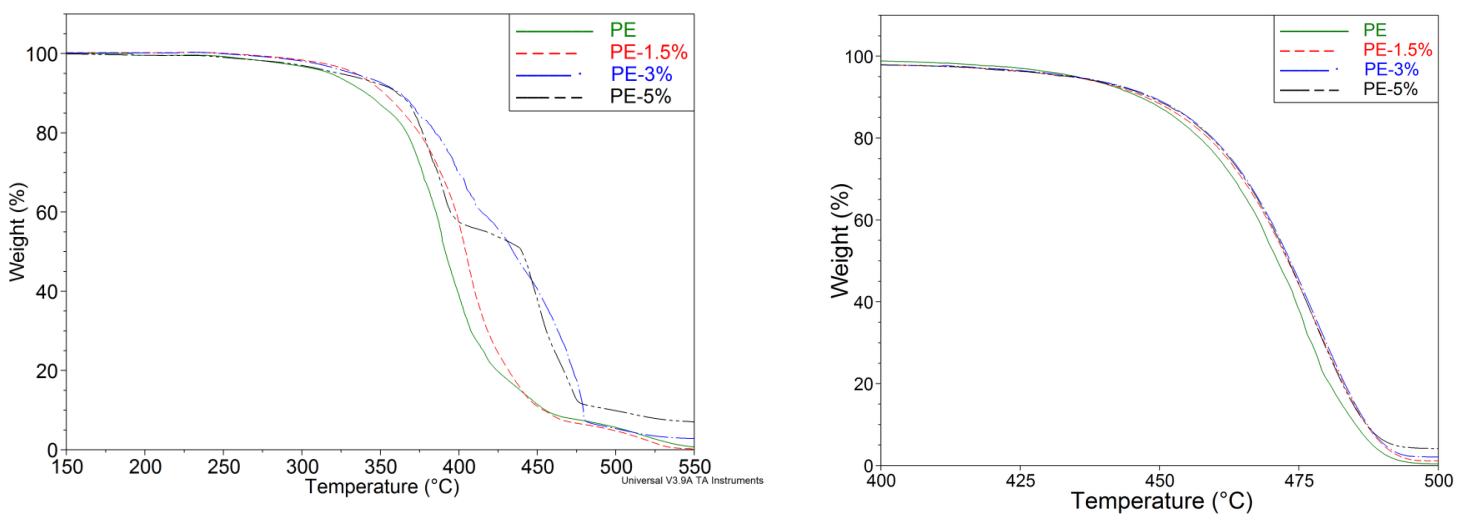

Fig. 4. TGA analysis for PE and PE/MMT-EA nanocomposites under air (a) and nitrogen (b) flow

elimination reaction can catalyze the degradation of polymer matrixes and reduce the thermal stability of polymer/clay nanocomposites [12]. We can therefore summarize that the modified clay plays two opposite roles in the thermal stability of the polymer/clay nanocomposites. One of them is its barrier effect which should improve the thermal stability, and the second is the catalysis effect towards the degradation of the polymer matrix which would decrease the thermal stability.

The thermal stability of polymeric materials is usually studied by thermogravimetric analysis

Table 3. TGA data for PE, PP and their nanocomposites under air and nitrogen flow

\begin{tabular}{|c|c|c|c|}
\hline \multirow{2}{*}{ Sample } & \multicolumn{4}{|c|}{ Temperature $\left({ }^{\circ} \mathrm{C}\right)$ at weight loss under air flow } \\
\cline { 2 - 4 } & $5 \%$ & $10 \%$ & $50 \%$ \\
\hline PE & 318.6 & 340.8 & 391.4 \\
\hline PE-1.5\% & 334.5 & 352.3 & 404.4 \\
\hline PE-3\% & 333.3 & 362.5 & 434.6 \\
\hline PE-5\% & 324.6 & 360.6 & 440.3 \\
\hline PP & 255.5 & 267.0 & 308.9 \\
\hline PP-1.5\% & 263.2 & 283.9 & 347.1 \\
\hline PP-3\% & 249.6 & 263.2 & 328.1 \\
\hline PP-5\% & 256.2 & 274.9 & 342.3 \\
\hline \multirow{2}{*}{ Sample } & Temperature ( ${ }^{\circ}$ C) at weight loss under \\
\cline { 2 - 4 } & $5 \%$ & $10 \%$ & $50 \%$ \\
\hline PE & 436.4 & 446.4 & 471.2 \\
\hline PE-1.5\% & 434.6 & 447.4 & 473.0 \\
\hline PE-3\% & 435.0 & 448.7 & 473.4 \\
\hline PE-5\% & 434.2 & 448.3 & 473.2 \\
\hline PP & 419.7 & 430.9 & 454.0 \\
\hline PP-1.5\% & 419.2 & 432.3 & 457.9 \\
\hline PP-3\% & 426.4 & 435.0 & 453.8 \\
\hline PP-5\% & 420.1 & 430.7 & 450.6 \\
\hline
\end{tabular}

(TGA). The weight loss due to the formation of volatile products after degradation at high temperature is monitored as a function of temperature. The most important parameters which are taken into consideration include the onset temperature of the degradation (which is measured at $5 \%$ and $10 \%$ of the weight loss of the sample) and the $50 \%$ degradation temperature.

Figure $4 \mathrm{a}$ and Figure $4 \mathrm{~b}$ show the TGA analysis of PE and the PE/MMT-EA nanocomposites with 1.5, 3 and 5\% MMT-EA contents under air and nitrogen flow respectively. In Figure $4 \mathrm{a}$ can be observed that the PE/MMT-EA nanocomposites showed delayed decomposition compared to PE. The initial thermo-oxidative decomposition temperature for all $\mathrm{PE}$ nanocomposites is significantly higher than for the virgin PE. The decomposition temperature at $50 \%$ weight loss of the virgin polyethylene is about $391{ }^{\circ} \mathrm{C}$, and the $\mathrm{PE} /$ MMT-EA nanocomposites containing 1.5, 3 and 5 $w t \%$ organoclay occurred at 404,434 and $440^{\circ} \mathrm{C}$ respectively (Table 3 ). This corresponds very well with previous investigations. MMT-EA possesses high thermal stability and its layer structure exhibits great barrier effect to stop the evaporation of the small molecules generated in the thermooxidative decomposition process [12]. When the heating was performed under an inert gas flow, a non-oxidative degradation occurred (Figure 4b). The process for neat PE and for the PE/MMT-EA nanocomposites was similar (Table 3 ).

Figure 5a represents the TGA analysis of a PP/MMT-EA nanocomposite, compared with virgin PP when the analyses were conducted under air flow. It shows that the thermal stability of the nanocomposite is enhanced in comparison with that of pure PP. The most likely explanation is that higher decomposition temperature of the or- 

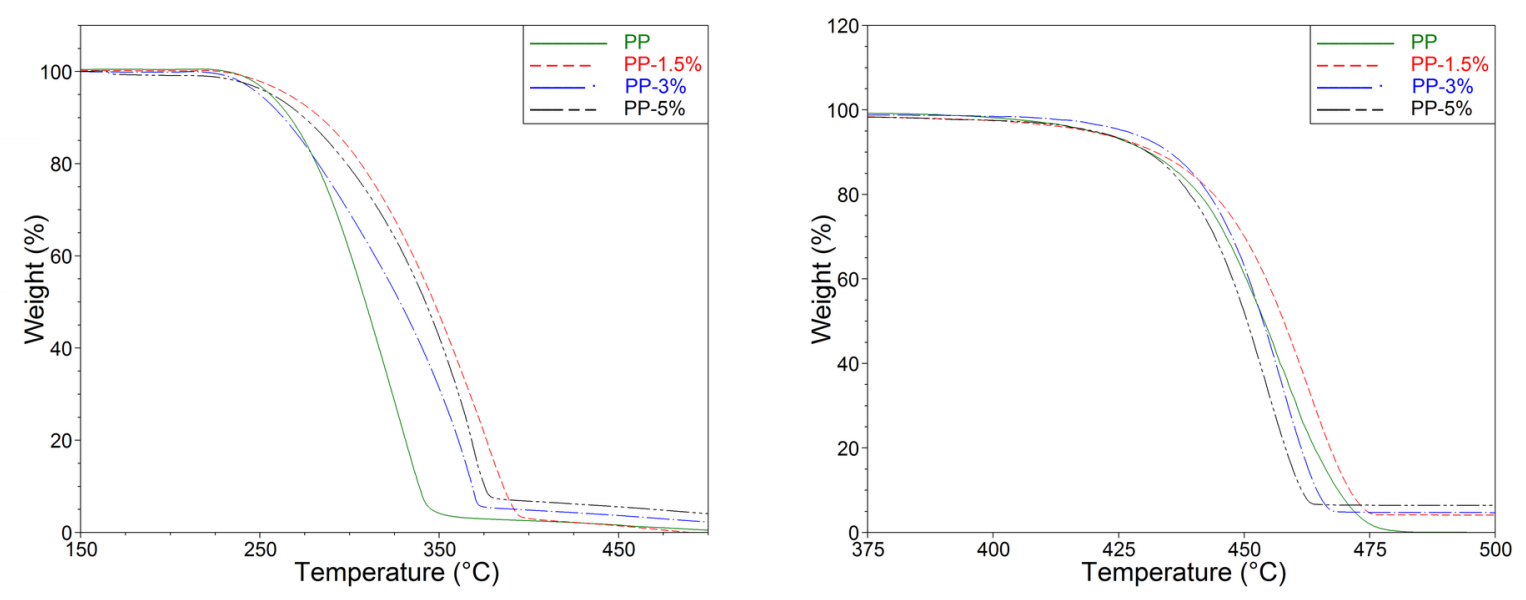

Fig. 5. TGA analysis for PP and PP/MMT-EA nanocomposites under air (a) and nitrogen (b) flow

gano - modified montmorillonite allows for the formation of char at an earlier time in order to retain the PP. In the case of organo-clay, char formation occurs earlier and can be broken up by the time in which the polymer degrades. The nanocomposites based on PP exhibit different decomposition temperature increase at $50 \%$ weight loss ranging from 19 to $38^{\circ} \mathrm{C}$ (Table 3). The shift of the degradation temperature may be ascribed to a decrease in oxygen and volatile degradation products permeability/diffusivity due to the homogeneous incorporation of clay sheets, to a barrier of these high-aspect ratio fillers, and char formation.

The thermal stability of PP and PP/clay nanocomposites tested by TGA in nitrogen atmosphere are shown in Figure 5b. The decomposition of the PP matrix in nanocomposites were similar to that of neat PP. For all nanocomposites with PP matrix the decomposition achieved a maximum rate at about $475^{\circ} \mathrm{C}$.

It is clearly seen that the increase in the onset of decomposition occurs for nanocomposites at low filler content when the heating takes place in air atmosphere. In our research this phenomenon can easily be observed in the case of a filler content of $1.5 \mathrm{wt} . \%$ for PP/MMT-EA nanocomposites and of 3 wt.\% for PE/MMT-EA, when intercalating an organoclay is well compatible with the polymer. This is another very much desired characteristic of nanocomposites in which the thermal properties' improvement corresponds with a low filler content, often making the obtained material cheaper, lighter and easier to process than more conventional microcomposites. Another key factor that may determine the extent of the thermal stabilization in nanocomposites could also arise from the actual nature of the thermal degradation mechanism, often different from one polymer to another. Without any doubt, the chemical nature of the studied polymeric material and its degradation mechanism play an important role here. It can be seen that not only the content of the nanofiller has influence on thermal stability of the researched materials but also dispersion and the morphological structure is important. For this reason, thermal stability of the PE- and PP-based nanocomposites depends on difference in chemical [8].

\section{CONCLUSIONS}

The scope of this research was to examine the formation of new organic-inorganic nanocomposites and their structure and thermal properties.

Modification process of MMT exhibits a increase of d-spacing of MMT layer which results in good compatibility with polyolefins.

The X-ray results revealed significant information that PE/MMT-EA and PP/MMT-EA nanocomposites, prepared by melt intercalation of polyolefins in the presence of a reactive organofilic clay, represent exfoliated type of structure.

The exfoliation of clay leads to an improved thermal stability of the nanocomposites. The higher onset decomposition temperature of depicted nanocomposites can be the result of chemical interaction between the polymer matrix and the clay layer surface during thermal degradation. In the presence of MMT layers strongly interacting with polymer matrix the motions of polymer chains are limited. This effect brings additional stabilization in the case of polymer/ MMT nanocomposites. 
These improved properties are generally attained at very low filler loading $(1.5 \mathrm{wt} \%)$. For these reasons, they are competitive with other materials for specific applications.

Generally, we can conclude that the thermal stability of polymeric nanocomposites containing modified MMT is related to the organoclay content and dispersion.

\section{REFERENCES}

1. Alexandre M. and Dubois P. Polymer-layered silicate nanocomposites: preparation, properties and uses of a new class of materials. Materials Science and Engineering, 28(1-2), 2000, 1-63.

2. Chen G., Liu S., Chen S. and Qi Z. FTIR spectra, thermal properties, and dispersibility of a polystyrene/ montmorillonite nanocomposite. Macromolecular Chemistry and Physics, 202(7), 2001, 1189-1193.

3. Filho F.G.R., Melo T.J.A., Rabello M.S. and Silva S.M.L. Thermal stability of nanocomposites based on polypropylene and bentonite. Polymer Degradation and Stability, 89(3), 2005, 383-392.

4. Gilman J.W., Award W.H., Davis R.D., Shields J., Harris Jr R.H., Davis Ch., Morgan A.B., Sutto T.E., Callahan J., Trulove P.C. and DeLong H.C. Polymer/layered silicate nanocomposites from thermally stable trialkylimidazolium- treated montmorillonite. Chemistry of Materials, 14(9), 2002, 3776-3785.

5. Gopakumar T.G., Lee J.A., Kontopoulou M. and Parent J.S. Influence of clay exfoliation on the phys- ical properties of montmoryllonite/polyethylene composites. Polymer, 43(20), 2002, 5483-5491.

6. Huang J.Ch., Zhu Z.K., Yin J., Qian X.F. and Sun Y.Y. Poly(etherimide)/montmorillonite nanocomposites prepared by melt intercalation: morphology, solvent resistance properties and thermal properties. Polymer, 42(3), 2001, 873-877.

7. Lee S.R., Park H.M., Lim H., Kang T., Li X., Cho W.J. and Ha Ch.S. Microstructure, tensile properties, and biodegradability of aliphatic polyester/clay nanocomposites. Polymer, 43(8), 2002, 2495-2500.

8. Leszczyńska A., Njuguna J., Pielichowski K. and Banerjee J.R. Polymer/montmorillonite nanocomposites with improved thermal properties Part I. Factors influencing thermal stability and mechanisms of thermal stability improvement. Thermochimica Acta, 453(2), 2007, 75-96.

9. Nour M.A. Polymer/clay nanocomposites. Polimery, 47(5), 2002, 326-331.

10. Suberlyak O., Krasinskyi V., Moravskyi V., Gerlach H. and Jachowicz T.: Influence of aluminosilicate filler on the physicomechanical properties of polypropylene-polycaproamide composites. Materials Science 50(2), 2014, 296-302.

11. Xie W., Gao Z., Pan W., Hunter D., Singh A. and Vaia R. Thermal degradation chemistry of alkyl quaternary ammonium montmorillonite. Chemistry of Materials, 13(9), 2001, 2979-2990.

12. Zhao Ch., Qin H., Gong F., Feng M., Zhang S. and Yang M. Mechanical, thermal and flammability properties of polyethylene/clay nanocomposites. Polymer Degradation and Stability, 87(1), 2005, 183-189. 